\title{
Influence of the El Niño-Southern Oscillation on the probability of dry and wet seasons in Spain
}

\author{
D. Muñoz-Díaz, F. S. Rodrigo* \\ Department of Applied Physics, University of Almería, La Cañada de San Urbano s/n, 04120 Almería, Spain
}

\begin{abstract}
Agricultural and water management is usually based on probabilities of seasonal or monthly rainfall, the quantity of which is commonly grouped into 3 categories: drought, normal, and abundant. Changes in the probability of rainfall amounts will influence decision-making by farmers and water managers. This study explores the changes induced by the El Niño-Southern Oscillation (ENSO) on the probability of seasonal rainfall in Spain. We analyzed the seasonal ENSO index, divided into 3 phases: positive (La Niña), neutral, and negative (El Niño). Seasonal rainfall in Spain for 1912-2000 was divided into 3 groups corresponding to each ENSO phase. Resulting empirical distribution functions allow an estimate of the changes in the probability of seasons being wet or dry that are due to changes in the ENSO phase. The analysis was made considering contemporaneous seasons, and rainfall series lagged 1 and 2 seasons. ENSO affects rainfall in Spain as follows: (1) In autumn, El Niño leads to a null probability of drought, while La Niña leads to a low probability of wet conditions in the whole country, except in the north; in the Mediterranean area in the following spring, an autumn El Niño leads to drought and an autumn La Niña to a null probability of drought. (2) In winter there is no ENSO influence, perhaps as a consequence of the predominance of the North Atlantic Oscillation (NAO). (3) In spring, La Niña leads to a low probability of drought in the north. (4) In summer, La Niña leads to drought in SW Spain, as well as in the north in the following winter; in addition, in the following autumn there are low probabilities of drought after El Niño, and of wet conditions after La Niña.
\end{abstract}

KEY WORDS: ENSO $\cdot$ Seasonal rainfall $\cdot$ Extreme events $\cdot$ Spain

\section{INTRODUCTION}

El Niño-Southern Oscillation (ENSO) is the major coupled air-sea phenomenon on a 2 to 8 yr time scale (Philander 1990). This coupled mode is characterized by a see-saw in sea level pressure (SLP) between the eastern and western tropical Pacific, associated with extremes in sea surface temperature (SST) anomalies in the central and eastern equatorial Pacific (Rasmusson \& Carpenter 1982). Warm ENSO events correspond to one phase of the phenomenon during which the pressure difference across the tropical Pacific is reduced and the SST anomalies are positive in the central to eastern tropical Pacific. The contrasting cold ENSO events have an enhanced SLP gradient across the tropical Pacific and negative SST anomalies in the central to eastern tropical Pacific. These changes are associated with global-scale climate anomalies through the whole tropical zone and often over much of the extratropical zones, mainly around the North Pacific (e.g. Ropelewski \& Halpert 1987, 1996, Hamilton 1988, Kiladis \& Díaz 1989, Halpert \& Ropelewski 1992, Yulaeva \& Wallace 1994, Díaz et al. 2001).

The impact of ENSO on the North Atlantic domain is much weaker and less robust than in the Pacific region (Fraedrich 1990, 1993, Fraedrich \& Müller 1992, May \& Bengtsson 1998, Moron \& Ward 1998, Dong et al. 2000, Pozo-Vázquez et al. 2001). However, relationships exist between ENSO and European climate at the interannual and the intraseasonal time scale (e.g. Van Loon \& Madden 1981, Fraedrich \& Müller 1992, Wilby 1993, Gershunov \& Barnett 1998, Bailey 1998, Moron \& Ward 1998, Van Oldenborgh et al. 2000, Moron \& Plaut 2003). The mean SLP pattern over the North Atlantic 
and Europe during warm (cold) ENSO events presents a generally negative (positive) SLP over the central North Atlantic and a positive (negative) one north of $60^{\circ} \mathrm{N}$. This pattern is consistent with a weakening (strengthening) of the normal north-south SLP gradient across the North Atlantic and thus a negative (positive) phase of the North Atlantic Oscillation (NAO) during the warm (cold) ENSO events (Moron \& Gouirand 2003, Pozo-Vázquez et al. 2005).

For the warm ENSO phase, low surface temperatures and precipitation are observed in Scandinavia, while wet and warm conditions tend to prevail in SW Europe (Knippertz et al. 2003). In the spring season following a cold event, temperatures are lower than normal over western Europe and NW Africa. ENSO strongly influences precipitation in spring, with reduced (enhanced) rainfall in NW Africa and the eastern parts of the Iberian Peninsula after a warm (cold) event, and opposite anomalies in central Europe (Knippertz et al. 2003). The basic mechanism for the interaction between ENSO and precipitation in Europe is poorly understood. It may be related to ENSO-induced SST anomalies in the tropical North Atlantic, an effect that is strongest in boreal spring (March-April-May) (Lloyd-Hughes \& Saunders 2002).

In previous studies on the relationship between ENSO and Spanish rainfall, Laita \& Grimalt (1997) found that during the March-April period following the warm ENSO phase there was a decrease in the number of cyclonic days and the number of days with negative pressure anomaly in the Spanish Mediterranean area. Rodó et al. (1997) found an El Niño associated signal in stations in the ESE of the Iberian Peninsula, with a delay of 3 to 21 mo between ENSO onset in winter and the moment when its impact is detectable in rainfall series; the strongest ENSO signals were recorded in spring and secondarily in autumn, coinciding with the periods of rainfall maxima. Rodríguez-Puebla et al. (1998) identified a region in the SE Iberian Peninsula where annual rainfall is moderately correlated with an index of ENSO in October of the previous year. Rocha (1999) found the strongest El Niño rainfall correlations for spring in the Mediterranean coast of the peninsula, with belownormal precipitation in the spring following the year of an ENSO event. According to Rocha (1999), rainfall in the region might only respond to extreme conditions in the tropical Pacific, as measured by the Southern Oscillation Index (SOI).

Most of these studies analyzed the correlations for lags of up to 9 mo. The percentage of variability explained for a particular season varied between 6 and $10 \%$ (Rodó et al. 1997). The use of linear regressions is based on the assumption of a symmetrical response in the predictand to predictors of opposite sign. Pozo-
Vázquez et al. (2001) proposed an asymmetric response of the NAO to El Niño and La Niña. This indicates a need for alternative methods, e.g. composite analysis. In this study we use a methodology that does not make any specific assumptions about the link between rainfall and ENSO. The temporal stability of the El Niño rainfall anomalies in the Iberian Peninsula appears to be related to extreme atmospheric conditions in the tropical Pacific as measured by ENSO (Rodó et al. 1997). Therefore, our study was focused on extreme ENSO phases, with similar methodology as that employed in Muñoz-Díaz \& Rodrigo (2004a) on the impacts of NAO on winter rainfall in Spain.

Many agricultural and water management activities are planned on the basis of climatic categories of monthly and seasonal rainfall. For this reason, knowledge of the changes in the probability for climatic categories due to evolution of ENSO are useful for management. The main objective of this study was to explore whether ENSO alters frequencies of extreme rainfall events over Spain. An improved understanding of the sub-regional linkages between precipitation and climate teleconnection patterns may also enhance the skill of long-lead forecasts for the region (Brown \& Comrie 2002). The study is focused on identifying the nature of subregional precipitation variability in Spain and on quantifying relationships to the ENSO index. The priority is to know whether a given phase of ENSO increases or decreases the probability of 3 seasonal rainfall categories: drought, normal or abundant rainfall. These categories are constructed using the percentile values of rainfall distribution during a reference period. The analysis of seasonal rainfall was applied to a set of 32 rain gauges covering the whole country for the period 1912-2000, on a seasonal time scale, which is commonly used for climate prediction studies and for planning and management activities. Although some authors favor studying the ENSO impact on a monthly basis (Moron \& Gouirand 2003), ENSO variability in the northern extratropical regions can be identified more readily when averages are taken over the entire seasons of the year (Trenberth \& Hurrell 1994), since noise associated with natural weather variability is higher at monthly time scales.

\section{DATA}

\subsection{Rainfall series in Spain}

The database used in this study comprises seasonal total amounts of rainfall for 32 stations evenly distributed over Spain. Because of the high degree of seasonality of rainfall in the Iberian Peninsula, these analyses were made for each season of the year: winter values 
refer to December-January-February (DJF), spring is March-April-May (MAM), summer is June-JulyAugust (JJA), and autumn is September-OctoberNovember (SON). Table 1 lists the meteorological stations and the mean seasonal rainfall $(\mathrm{mm})$ for 1961-1990. The stations were selected from a list of rain gauges supplied by the Spanish Institute of Meteorology (INM), on the basis of record length and completeness, and to provide a reasonable coverage of Spain. Most stations have not changed position, but the metadata relative to methods and instruments is known for only a few. Almarza et al. (1996) and Esteban-Parra et al. (1998) analyzed the homogeneity of these series by applying absolute homogeneity tests (Thom and Mann-Kendall tests) and relative homogeneity tests (Barlett and Alexanderson tests), and they concluded that these series are high quality and do not possess heterogeneity problems. A complete record for the 1912-2000 study period exists at 13 stations, and missing data are $<5 \%$ for the other rain gauges. Mete-

Table 1. Seasonal rainfall data (mean, $\mathrm{mm}$ ) for 32 meteorological stations in Spain for the reference period 1961-1990. Altitude, longitude and latitude of the stations are listed in Muñoz-Díaz \& Rodrigo (2004a, their Table 2)

\begin{tabular}{|c|c|c|c|c|}
\hline \multirow[t]{2}{*}{ Stn } & \multicolumn{4}{|c|}{ Rainfall } \\
\hline & Winter & Spring & Summer & Autumn \\
\hline Albacete (AB) & 81.7 & 122.8 & 59.6 & 103.9 \\
\hline Almeria (AL) & 69.2 & 58.4 & 10.0 & 68.0 \\
\hline Alicante (A) & 81.4 & 91.5 & 34.9 & 149.7 \\
\hline Badajoz (BA) & 181.6 & 128.5 & 32.7 & 144.5 \\
\hline Barcelona (B) & 137.8 & 161.8 & 112.3 & 233.4 \\
\hline Burgos (BU) & 157.3 & 173.0 & 95.5 & 148.5 \\
\hline Caceres (CC) & 189.4 & 129.4 & 40.8 & 151.2 \\
\hline Ciudad Real (CR) & 153.3 & 129.2 & 47.2 & 121.3 \\
\hline Cuenca (CU) & 163.3 & 160.1 & 86.7 & 154.0 \\
\hline Granada (GR) & 142.9 & 109.1 & 24.2 & 107.7 \\
\hline Huelva $(\mathrm{H})$ & 223.0 & 111.1 & 19.2 & 160.4 \\
\hline Huesca (HU) & 132.6 & 167.2 & 115.8 & 173.0 \\
\hline Jaen $(J)$ & 220.7 & 164.8 & 33.9 & 143.2 \\
\hline La Coruña (LC) & 364.3 & 247.8 & 102.8 & 282.6 \\
\hline Logroño (LO) & 84.6 & 120.2 & 88.7 & 93.2 \\
\hline Madrid (M) & 142.4 & 127.5 & 48.0 & 138.9 \\
\hline Malaga (MA) & 255.5 & 122.0 & 20.2 & 184.3 \\
\hline Murcia (MU) & 65.1 & 91.7 & 35.5 & 100.1 \\
\hline Pamplona (P) & 248.6 & 226.8 & 142.9 & 232.3 \\
\hline Salamanca (SA) & 109.3 & 105.4 & 62.7 & 112.7 \\
\hline S. Fernando (SF) & 250.4 & 125.8 & 19.2 & 186.9 \\
\hline S. Sebastian (SS) & 458.4 & 414.6 & 285.0 & 431.5 \\
\hline Santander (S) & 374.3 & 316.1 & 201.3 & 384.8 \\
\hline Santiago (SC) & 793.9 & 468.1 & 154.4 & 506.0 \\
\hline Segovia (SG) & 124.2 & 133.7 & 75.0 & 129.3 \\
\hline Sevilla (SE) & 248.8 & 144.7 & 29.2 & 185.1 \\
\hline Soria (SO) & 141.3 & 143.5 & 101.9 & 129.1 \\
\hline Toledo (TO) & 109.5 & 111.9 & 49.0 & 104.0 \\
\hline Tortosa (TT) & 111.9 & 138.7 & 87.0 & 223.5 \\
\hline Valencia (V) & 108.1 & 105.4 & 52.3 & 199.1 \\
\hline Valladolid (VA) & 133.1 & 122.9 & 67.0 & 120.7 \\
\hline Zaragoza (Z) & 66.0 & 93.7 & 63.4 & 92.4 \\
\hline
\end{tabular}

orological stations are located at longitudes from $8^{\circ} 26^{\prime} \mathrm{W}$ (Santiago de Compostela) to $2^{\circ} 04^{\prime} \mathrm{E}$ (Barcelona), latitudes from $43^{\circ} 27^{\prime} \mathrm{N}$ (Santander) to $36^{\circ} 27^{\prime} \mathrm{N}$ (San Fernando), and altitudes from $6 \mathrm{~m}$ a.s.l. (Barcelona) to $1080 \mathrm{~m}$ a.s.l. (Soria). To avoid masking of the results by different geographical conditions and to eliminate possible scale effects, the variables were standardized, using the period 1961-1990 as reference, with:

$$
y_{i}(t)=\frac{x_{i}(t)-\overline{x_{i}}}{\sigma_{i}}
$$

where $y_{i}(t)$ is seasonal rainfall anomaly at station $i$ in year $t, x_{i}(t)$ is seasonal rainfall at Stn $i$ in Year $t$, and $\bar{x}_{i}$ and $\sigma_{i}$ are the mean and $\mathrm{SD}$, respectively, of the reference period. Normalization was based on the period 1961-1990, following WMO suggestions to establish a $30 \mathrm{yr}$ period for the definition of climate normals (Ojo \& Afiesimama 2000), and to take into account that projections on climate change (e.g. Hulme \& Sheard 1999) use this period as reference and express future climate changes as percentages of the values for this period.

\subsection{Seasonal ENSO index}

This study is based on the SOI, calculated as the series of standardized differences in monthly SLP between Tahiti and Darwin (Ropelewski \& Jones 1987). Most ENSO events begin between March and September and end between February and March, with the peak of the anomalies during the northern winter (Trenberth 1997). Thus, if an ENSO event is extreme, and well developed during autumn, it can be expected to persist until the following winter. PozoVázquez et al. (2005) selected those ENSO events that are considered extremes and that were well developed during the previous season (i.e. for autumn, they selected extreme ENSO events that were well developed during the previous summer). Lucero (1998) used a 5 mo moving average of the ENSO to describe the evolution of the Southern Oscillation. Brown \& Comrie (2002) used seasonal averages of the ENSO to investigate the relationship with seasonal totals for precipitation in the SW USA. Therefore, it is interesting to study the role of the ENSO in the four seasons of the year.

Monthly values of SLP for Tahití and Darwin were obtained from the Climate Research Unit, University of East Anglia (available at: www.cru.uea.ac.uk/cru/data/ soi.htm). These values were standardized using the 1961-1990 reference period. Owing to the different climatic characteristics of the 2 stations and owing to the change of both mean and SD throughout the year, normalization is necessary to avoid creating a biased and misleading index (see Trenberth 1984). The SOI 
is defined as the difference between the normalized pressure series. Monthly data were averaged to obtain a seasonal index. The ENSO indexes obtained were not, in general, $I=0 \pm 1$, due to the normalization, but the indexes' distributions were not significantly different from normal (Kolmogorov-Smirnov test). The correlation coefficients between SOI index and an index based on SST (El Niño3 index) were significant at a $95 \%$ confidence level ( $\mathrm{R}$ of -0.84 for winter, -0.72 for spring, -0.71 for summer, -0.81 for autumn).

If we accept the Gaussian distribution of the index, then the values are distributed symmetrically around the mean. In this study, the evolution of ENSO was divided into 3 phases: (1) negative ENSO (El Niño) when $I<\bar{I}-1$, where $\bar{I}$ is the mean value of the index; (2) neutral ENSO (ENSOn) when $\bar{I}-1 \leq I \leq \bar{I}+1$; and (3) positive ENSO (La Niña) when $I>\bar{I}+1$. Extreme ENSO phases were thus defined as deviations $>1$ SD in the reference period 1961-1990. Note that threshold values to define extreme phases of the ENSO generally differ from \pm 1 (winter: $-0.82,+1.18$; spring: $-1.04,+0.96$; summer: $-0.89,+1.11$; autumn: $-1.03,+0.97)$. This analysis was made for the indices corresponding to the period 1866-2000, to obtain threshold values corresponding to the longest possible period and to avoid effects of fluctuations in ENSO in the last part of the record on the determination of the threshold values. Fig. 1 shows the histogram of the ENSO for the 4 seasons of the year, the Gaussian distribution fitted, and the threshold values obtained to define the 3 ENSO phases.

The percentages of data falling within each phase during the period 1912-2000 are shown in Table 2. Table 3 shows the basic statistics for each ENSO phase and season of the year and the overall values for the period 1912-2000. Mean values of ENSOn are very similar to those for the complete 1912-2000 and 1866-2000 periods; SDs are very similar for El Niño and La Niña, and lower than those for to 1912-2000.

\section{ANALYSIS AND RESULTS}

\subsection{Regionalization of seasonal rainfall in Spain}

Cluster analysis (CA) was applied to the data in the same way as in Muñoz-Díaz \& Rodrigo (2004b). Clustering algorithms generally do not require the input database to conform to particular statistical distributions, because CA is more an objective method to quantify the characteristics of a set of observations than an inference statistical tool. Therefore, the requirements of normality and homoscedasticity, important in other multivariate techniques, do not necessarily apply to CA (Martínez Arias 1999). Rainfall series
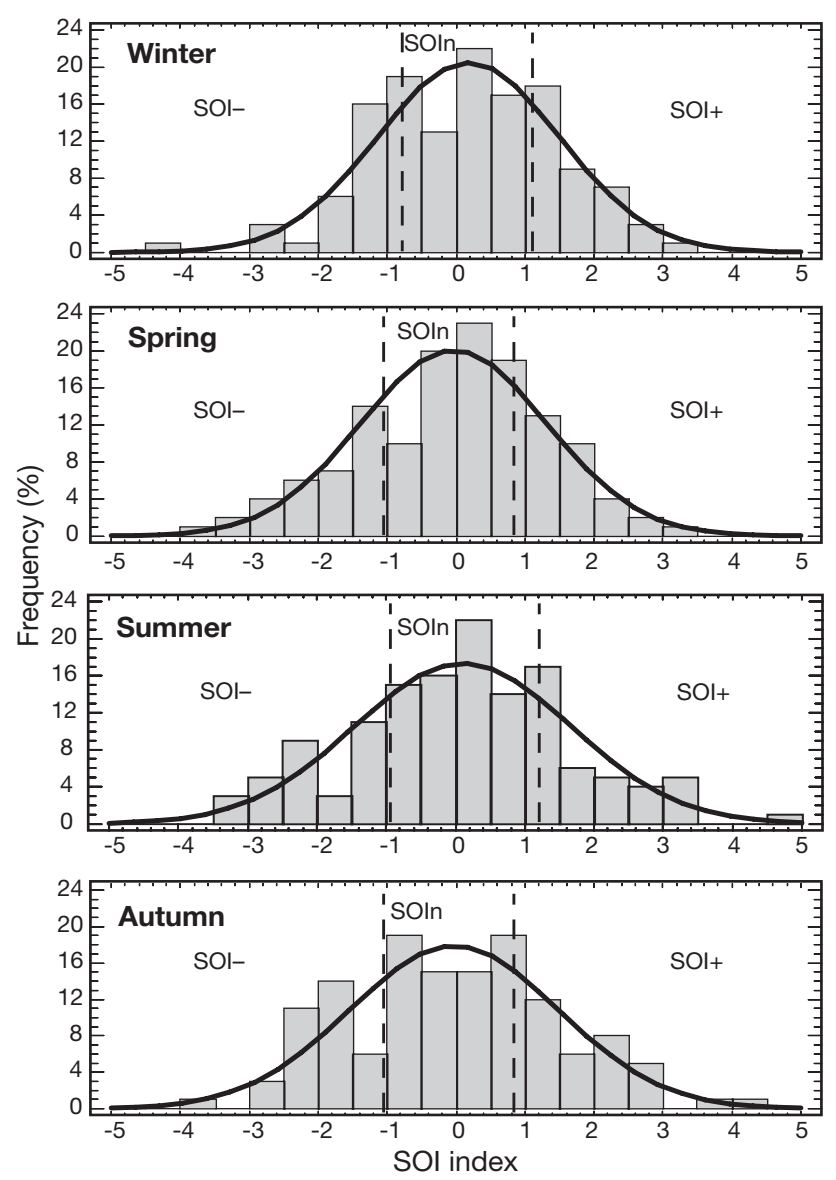

Fig. 1. Histogram of the seasonal ENSO indices for the period 1866-2000, Gaussian distribution fitted, and threshold values (vertical dashed lines) used to define the 3 ENSO phases for the 4 seasons of the year

in the Iberian Peninsula are best modelled by skewed distribution functions, such as the gamma distribution function (Lana \& Burgueño 2000). The purpose of CA is to place objects into groups not defined previously; the procedure is described in Muñoz-Díaz \& Rodrigo (2004b, their Sec. 3.1., and references therein). Fig. 2 shows the clusters obtained.

In winter, Cluster 1 is in western Iberia, Cluster 2 is along the Mediterranean coast, and Cluster 3 is associated with the northern coast; the climatic patterns corresponding to these clusters are described in MuñozDíaz \& Rodrigo (2004b, their Sec. 3.1.).

Table 2. Percentage of data for the 1912-1990 period falling within each of the ENSO categories

\begin{tabular}{|lccc|}
\hline & El Niño & ENSOn & La Niña \\
\hline Winter & 21.3 & 52.8 & 25.8 \\
Spring & 25.8 & 53.9 & 20.2 \\
Summer & 22.5 & 52.8 & 24.7 \\
Autumn & 25.8 & 50.6 & 23.6 \\
\hline
\end{tabular}


Table 3. Mean value of ENSO $(\bar{I} \pm \mathrm{SD})$ for each phase and season during 1912-2000, and for the overall study periods $1912-2000$ and 1866-2000

\begin{tabular}{|lccccc|}
\hline & El Niño & ENSOn & La Niña & \multirow{2}{*}{$1912-2000$} & $1866-2000$ \\
\hline Winter & $-1.71 \pm 0.86$ & $+0.09 \pm 0.59$ & $+1.75 \pm 0.50$ & $+0.11 \pm 1.33$ & $+0.18 \pm 1.32$ \\
Spring & $-1.74 \pm 0.53$ & $+0.04 \pm 0.49$ & $+1.64 \pm 0.57$ & $-0.10 \pm 1.26$ & $-0.04 \pm 1.35$ \\
Summer & $-1.95 \pm 0.71$ & $+0.01 \pm 0.52$ & $+2.00 \pm 0.92$ & $+0.07 \pm 1.52$ & $+0.11 \pm 1.56$ \\
Autumn & $-1.83 \pm 0.59$ & $-0.01 \pm 0.57$ & $+1.82 \pm 0.74$ & $-0.05 \pm 1.43$ & $-0.03 \pm 1.52$ \\
\hline
\end{tabular}

The inclusion of Portuguese data, which were not available for this study, would have enlarged Cluster 1 for autumn, winter and spring, and Cluster 4 for summer (cf. Rocha 1999, Goodess \& Jones 2002).

For each season and cluster, we determined the centroid series (i.e. the average for each cluster).

In spring, the winter pattern is largely repeated, but with an enlargement of Clusters 2 \& 3.

In summer, the spatial structure is different, perhaps because the NE region (Cluster 2) is affected by summertime incursions of maritime air and frontal disturbances around the northern flank of the Mediterranean summer antyciclone, while the SE region (Cluster 1), which has the lowest average precipitation, is not influenced by this mechanism (Sumner et al. 2001).

Autumn seems to be a transition season, with 4 clusters, but also with similarity to the winter pattern. This reflects the influence of convective and local storms in early autumn, and the westerly circulation from October onwards, which constitute the transition from summer to winter.
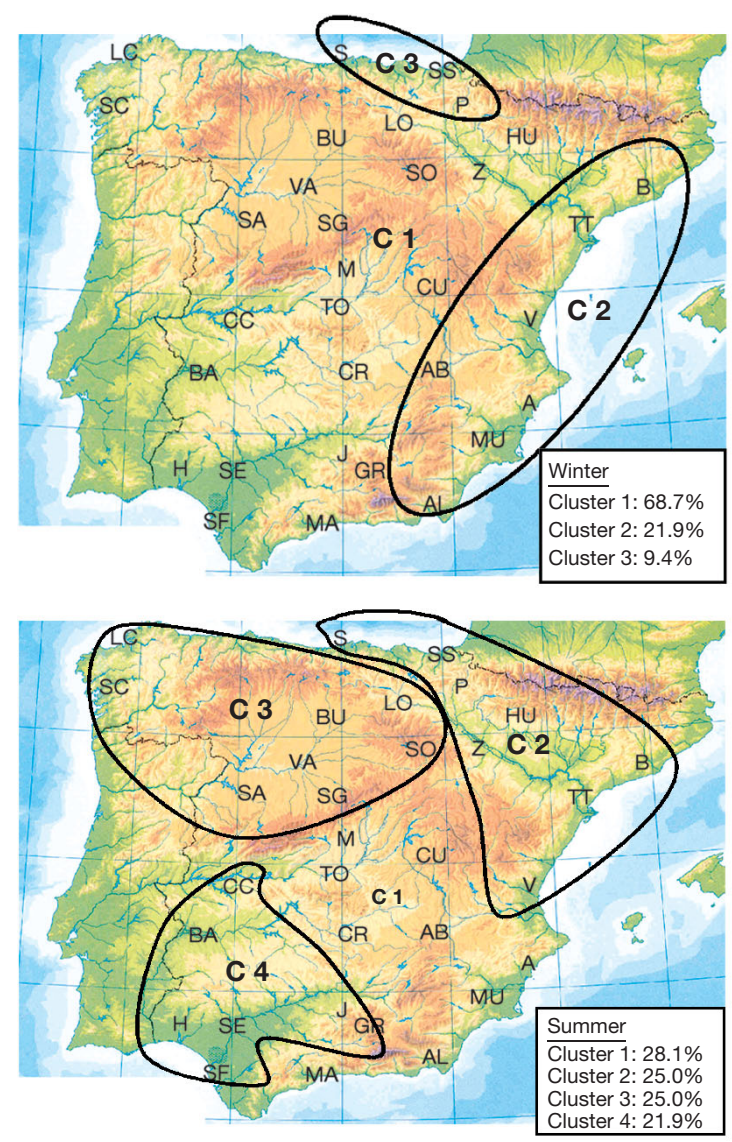

The series obtained were not significantly different from normal, according to the Kolmogorov-Smirnov test. The 25th (P25) and 75th (P75) percentiles of the reference period 1961-1990 were calculated to establish the threshold values needed to define dry seasons $(\mathrm{C}<\mathrm{P} 25)$, wet seasons $(\mathrm{C}>\mathrm{P} 75)$ and 'normal' seasons (P25 $\leq \mathrm{C} \leq \mathrm{P} 75)$.

\subsection{Changes in the probabilities of drought and abundant rainfall}

The historical impacts of ENSO on Spanish climate can be illustrated by calculating how often seasonal precipitation has been in the upper, middle and lower

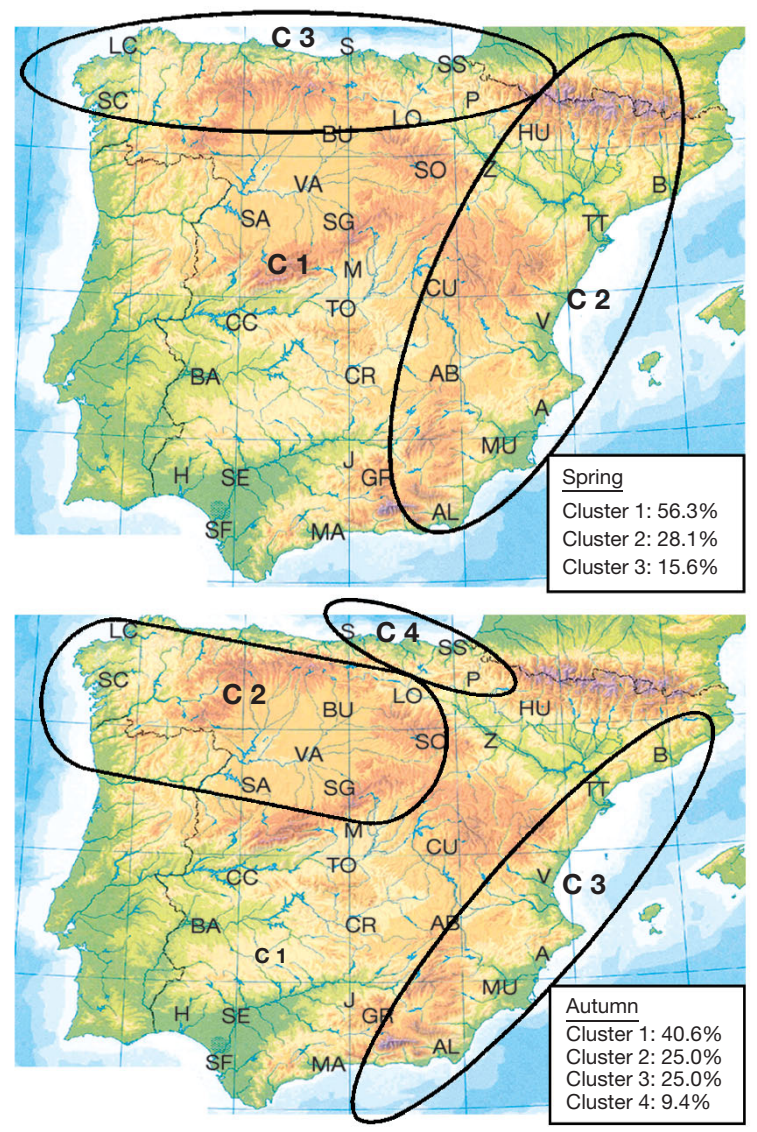

Fig. 2. Cluster analysis of 32 rain gauges in Spain (Ward's method, squared Euclidean distance) for the 4 seasons of the year. Inset: percentage of observations corresponding to each cluster. See Table 1 for station codes 
climatological terciles during ENSO extremes. This creates sets of ENSO values of $I$, that can be used to estimate the distribution function of the rainfall anomalies series $C_{i}$ conditional on these sets. A similar methodology was followed by Lucero (1998) in his analysis of the influence of ENSO on rainfall in central Argentina, and by Muñoz-Díaz \& Rodrigo (2004a), in their analysis on the influence of NAO on winter rainfall in Spain. The influence of changes in the ENSO phase on extreme rainfall events was assessed by investigating changes in the probability density functions. Small changes in mean climate variables can result in large changes in both the frequency and intensity of extreme events, due to the nonlinear relationships between means and extremes (Mearns et al. 1984, Wigley 1985). In addition, changes in the variance may occur and either complement or countervail the influence of mean changes on extremes (Katz \& Brown 1992). In this study, the probabilities of dry and wet seasons were computed from the empirical distributions for each series by classifying rainfall series according to the ENSO phases. For each cluster, the threshold values chosen to define rainfall categories are the 25th and 75th percentiles for the reference period 1961-1990.

Rainfall anomalies series were thus divided into 3 groups, corresponding to each ENSO phase, for each cluster. The sets corresponding to ENSO extremes have few data (Table 4). Therefore, a theoretical distribution function for each set of rainfall anomalies was not fitted, and the study was made using the conditional empirical distribution of precipitation anomalies. This analysis was carried out for rainfall series contemporaneous to ENSO events, and with lags of up 2 seasons. In each case, the steps of the analysis were the following:

(1) For each seasonal ENSO, the rainfall series corresponding to each cluster were divided into 3 groups, corresponding to El Niño, ENSOn, and La Niña years. This procedure was followed for contemporaneous series (lag $L=0)$ and for cluster series lagged with $\mathrm{L}=1$ and $L=2$. Thus, for example, the influence of the autumn ENSO index was studied in the rainfall series corresponding to autumn, and the following winter and spring. (2) Mean and SD of each series $\mathrm{C}_{i}$ were calculated. (3) A $t$-test to compare difference between

Table 4. Number of datasets corresponding to ENSO extremes, for the four seasons of the year

\begin{tabular}{|lcc|}
\hline & El Niño & La Niña \\
\hline Winter & 19 & 23 \\
Spring & 23 & 18 \\
Summer & 20 & 22 \\
Autumn & 23 & 21 \\
\hline
\end{tabular}

Table 5. Empirical distribution (mean \pm SD) and number of data (n) for the rainfall seasonal series corresponding to each cluster and the autumn ENSO phase, for lags $\mathrm{L}=0,1$, 2 seasons

\begin{tabular}{|lccc|}
\hline Cluster & $\begin{array}{c}\text { El Niño } \\
(\mathrm{n}=23)\end{array}$ & $\begin{array}{c}\text { ENSOn } \\
(\mathrm{n}=45)\end{array}$ & $\begin{array}{c}\text { La Niña } \\
(\mathrm{n}=21)\end{array}$ \\
\hline Autumn $(\mathbf{L}=\mathbf{0})$ & & & \\
C1 & $+0.38 \pm 0.60$ & $-0.08 \pm 0.63$ & $-0.44 \pm 0.59$ \\
C2 & $+0.41 \pm 0.73$ & $+0.05 \pm 0.75$ & $-0.30 \pm 0.62$ \\
C3 & $+0.21 \pm 0.63$ & $-0.13 \pm 0.56$ & $-0.32 \pm 0.49$ \\
C4 & $+0.15 \pm 0.71$ & $+0.12 \pm 0.95$ & $+0.17 \pm 0.89$ \\
Winter $(\mathbf{L}=\mathbf{1})$ & & & \\
C1 & $-0.16 \pm 0.81$ & $-0.06 \pm 0.86$ & $-0.35 \pm 0.64$ \\
C2 & $-0.17 \pm 0.72$ & $+0.06 \pm 0.73$ & $-0.14 \pm 0.68$ \\
C3 & $-0.07 \pm 1.26$ & $-0.09 \pm 0.95$ & $-0.44 \pm 1.02$ \\
Spring $(\mathbf{L}=\mathbf{2})$ & & & \\
C1 & $+0.04 \pm 0.77$ & $+0.14 \pm 0.81$ & $+0.19 \pm 0.81$ \\
C2 & $-0.40 \pm 0.62$ & $+0.02 \pm 0.71$ & $+0.21 \pm 0.65$ \\
C3 & $-0.36 \pm 0.55$ & $-0.25 \pm 0.97$ & $-0.04 \pm 0.60$ \\
\hline
\end{tabular}

means, and an F-test to compare variances were used to compare rainfall series that had been stratified in step (1) by season, cluster and ENSO phase. (4) In the cases where significant differences between means and/or variances were found, probabilities of dry and wet seasons were calculated. The threshold values used to define dry (wet) seasons were the 25th (75th) percentiles for the reference period 1961-1990. (5) To assess significance, a bootstrap technique was used (von Storch \& Zwiers 1999). This method involves a random resampling with replacement of the series for each season and ENSO phase. For each resampling, probabilities of dry and wet seasons were estimated. The 2.5 and 97.5 percentiles of the probability estimates provide a $95 \%$ confidence interval. The expected value in each category (assuming no relationship) would be $25 \%$. Therefore, a probability was considered as significant if this interval did not contain the value of $25 \%$.

\subsubsection{Autumn ENSO}

Table 5 shows the parameters of the empirical distributions for the rainfall series corresponding to each cluster and autumn ENSO phase, and Fig. 3 shows some representative cases, including the 25th and 75th percentiles of the reference period for each cluster. For autumn rainfall series the mean value corresponding to Cluster 1 (SW area), Cluster 2 (NW area), and Cluster 3 (Mediterranean area) shifts to lower values when the ENSO changes from the negative to the neutral to the positive phase, ranging from positive values for El Niño to negative ones for La Niña. However, this influence is slight if we compare the means to the percentiles of the reference period. In 


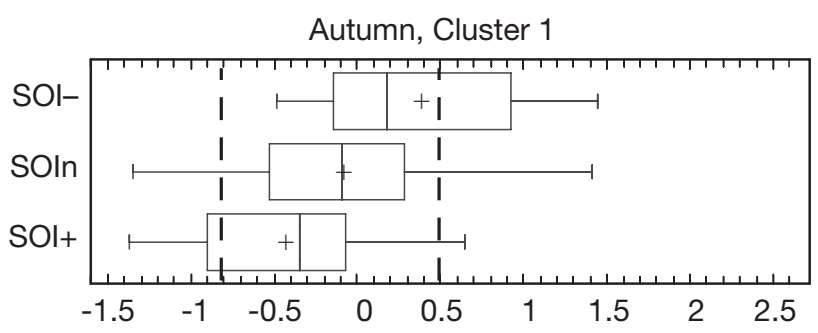

Autumn, Cluster 2

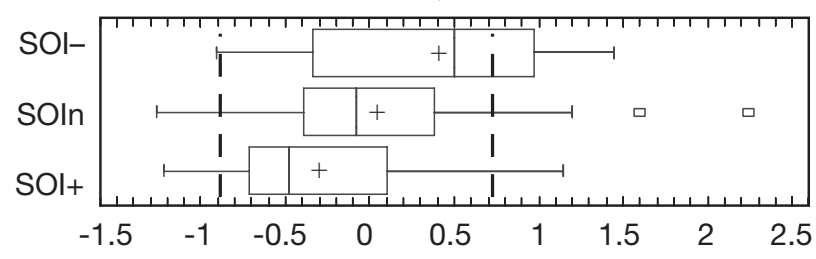

Autumn, Cluster 3

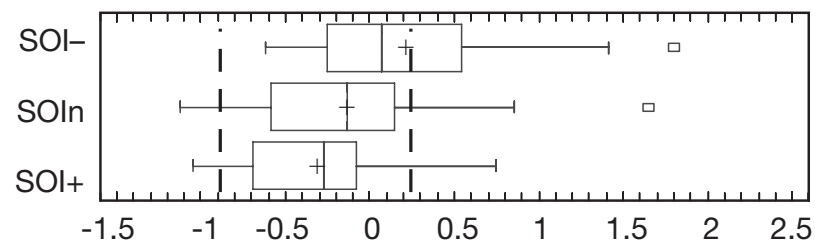

Spring, Cluster 2

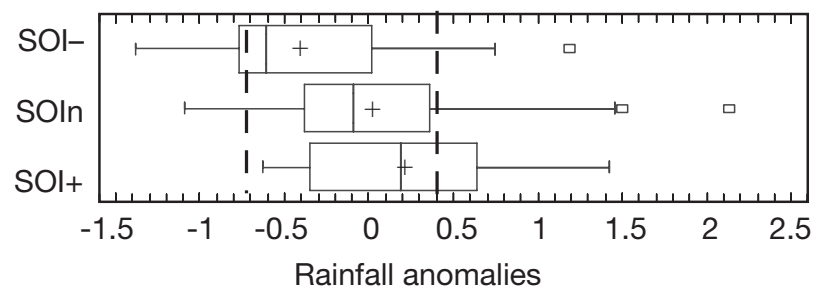

Fig. 3. Empirical distributions of seasonal rainfall in each cluster for the autumn ENSO phase, 1912-2000. Box shows the quartiles of the data; +: mean; vertical line in box: median; horizontal lines: $1.5 \times$ interquartile range; small squares: outliers; vertical dashed lines: quartiles of the reference period 1961-1990. Only the cases where significant differences were found are shown

the 3 cases, mean and median values lie inside the interquartile interval.

With a lag of 2 seasons, a clear influence is detected in the rainfall series of Cluster 2 for spring (Mediterranean area), where the mean changes from -0.40 for El Niño to +0.21 for La Niña.

The distributions were compared using a $t$-test and an $F$-test. In the 4 cases mentioned, there was a significant difference between the means of El Niño and La Niña, while there were no significant differences between variances (comparisons with ENSOn are not shown). Dry conditions under La Niña and wet conditions under El Niño in autumn have also been found by, for instance, Moron \& Ward (1998) and Rocha (1999). The reverse pattern of spring rainfall in the
Mediterranean area, i.e. dry conditions under autumn El Niño and wet conditions under autumn La Niña, confirms previous results by many studies (Laita \& Grimalt 1997, Rodó et al. 1997, Rodríguez-Puebla et al. 1998, Moron \& Ward 1998).

Table 6 shows the probability of dry and wet seasons for each cluster and the autumn ENSO phase. In autumn, probabilities of drought or abundant rainfall are similar for all 3 clusters, indicating that the ENSO phases influence the whole country. The significant results are the null probability of droughts under El Niño (except in the north), and the low probability of wet conditions under La Niña. In the following spring, a significant influence is detected only in the Mediterranean area (Table 6). Dry conditions under El Niño and null probability of droughts under La Niña are the main significant results.

\subsubsection{Winter ENSO}

The effects of winter ENSO on rainfall series in winter are summarized in Table 7 . In winter $(L=0)$ Clusters 1 (central and western area) and 3 (northern area) show more negative anomalies under La Niña than under El Niño. Pozo-Vázquez et al. (2005) detected negative anomalies of winter rainfall in SW and central areas of the Iberian Peninsula under winter La Niña conditions. This pattern is consistent with a positive phase of the NAO detected during cold ENSO events. However, there are no significant differences between different ENSO phases. The probabilities of drought and abundant rainfall (not shown) are very similar (Cluster 1: probability of drought is $37 \mathrm{vs.} 30 \%$, and of wet winters is 26 vs. $13.0 \%$, for El Niño and La Niña, respectively). Values for Cluster 2 (Mediterranean area) are very similar in Table 7 . This confirms the findings of Quadrelli et al. (2001), that there was not a connec-

Table 6. Empirical probability (\%) of dry $(\mathrm{C}<\mathrm{P} 25)$ and wet (C > P75) seasons for each autumn ENSO phase during 1912-2000. Threshold values are the 25th and 75th percentiles of the reference period 1961-1990. Only cases with significant differences between means and/or variances are shown (bold: significant probabilities at the $95 \%$ confidence level)

\begin{tabular}{|c|c|c|c|c|c|c|}
\hline \multirow[t]{2}{*}{ Cluster } & \multicolumn{2}{|c|}{ El Niño } & \multicolumn{2}{|c|}{ ENSOn } & \multicolumn{2}{|c|}{ La Niña } \\
\hline & Dry & Wet & Dry & Wet & Dry & Wet \\
\hline \multicolumn{7}{|l|}{ Autumn } \\
\hline C1 & 0.0 & 39.1 & 13.3 & 20.0 & 38.1 & 9.5 \\
\hline $\mathrm{C} 2$ & 13.0 & 39.1 & 15.6 & 13.3 & 28.6 & 9.5 \\
\hline C 3 & 0.0 & 30.4 & 20.0 & 15.6 & 23.8 & 9.5 \\
\hline \multicolumn{7}{|l|}{ Spring } \\
\hline $\mathrm{C} 2$ & 47.8 & 8.7 & 17.8 & 17.8 & 0.0 & 30.0 \\
\hline
\end{tabular}


Table 7. Empirical distribution (mean \pm SD) and number of data (n) for the rainfall seasonal series corresponding to each cluster and the winter ENSO phase, for lags $L=0,1,2$ seasons

\begin{tabular}{|cccc|}
\hline Cluster & $\begin{array}{c}\text { El Niño } \\
(\mathrm{n}=19)\end{array}$ & $\begin{array}{c}\text { ENSOn } \\
(\mathrm{n}=47)\end{array}$ & $\begin{array}{c}\text { La Niña } \\
(\mathrm{n}=23)\end{array}$ \\
\hline Winter $(\mathbf{L}=\mathbf{0})$ & & & \\
C1 & $-0.12 \pm 0.78$ & $-0.10 \pm 0.87$ & $-0.27 \pm 0.65$ \\
C2 & $-0.22 \pm 0.77$ & $+0.06 \pm 0.76$ & $-0.15 \pm 0.57$ \\
C3 & $-0.08 \pm 1.29$ & $-0.14 \pm 1.05$ & $-0.36 \pm 0.84$ \\
Spring $(\mathbf{L}=\mathbf{1})$ & & & \\
C1 & $0.00 \pm 0.83$ & $+0.13 \pm 0.81$ & $+0.18 \pm 0.77$ \\
C2 & $-0.30 \pm 0.76$ & $-0.03 \pm 0.68$ & $+0.10 \pm 0.66$ \\
C3 & $-0.40 \pm 0.60$ & $-0.13 \pm 0.87$ & $-0.35 \pm 0.81$ \\
Summer $(\mathbf{L}=\mathbf{2})$ & & & \\
C1 & $-0.10 \pm 0.72$ & $-0.26 \pm 0.61$ & $0.00 \pm 0.73$ \\
C2 & $+0.07 \pm 0.79$ & $+0.02 \pm 0.83$ & $+0.02 \pm 0.63$ \\
C3 & $+0.25 \pm 0.61$ & $-0.15 \pm 0.58$ & $+0.19 \pm 0.74$ \\
C4 & $-0.12 \pm 0.82$ & $-0.36 \pm 0.55$ & $+0.21 \pm 1.23$ \\
\hline
\end{tabular}

tion between Mediterranean precipitation patterns and El Niño anomalies during winter. This could be due to the predominance of NAO influence in winter (Muñoz-Díaz \& Rodrigo 2004a). The influence of ENSO, therefore, would be indirect, via the possible teleconnection with the NAO. This is a question that will be analysed in a future study.

The results for the following spring $(L=1)$ show no significant differences, although Cluster 2 (Mediterranean area) has a behaviour similar to that corresponding to the autumn ENSO index, i.e. negative anomalies under El Niño (mean value -0.30), and positive anomalies under La Niña (mean value +0.10). A similar result was detected by Knippertz et al. (2003). In summer, Cluster 1 (SE area) and Cluster 4 (SW area) show a similar behaviour, with a slight influence of negative anomalies under El Niño. Again, there are no significant differences between mean values and variances.

\subsubsection{Spring ENSO}

The results for spring ENSO and spring, summer, and autumn rainfall series are shown in Tables $8 \& 9$, and Fig. 4. Only in the case of Cluster 3 (northern area of the Iberian Peninsula) was there a significant difference between means $(-0.37$ under El Niño and +0.17 under La Niña). These mean values are within the interquartile range (Fig. 4). The low probability of a dry spring is significant (Table 9). In the following summer, the variances corresponding to Cluster 2 (NE area) and Cluster 3 (NW area) show a significant difference. In summer, the probability of wet conditions under a spring El Niño is slightly higher for these
Table 8. Empirical distribution (mean \pm SD) and number of data (n) for the rainfall seasonal series corresponding to each cluster and the spring ENSO phase, for lags $L=0,1,2$ seasons

\begin{tabular}{|lccc|}
\hline Cluster & $\begin{array}{c}\text { El Niño } \\
(\mathrm{n}=23)\end{array}$ & $\begin{array}{c}\text { ENSOn } \\
(\mathrm{n}=48)\end{array}$ & $\begin{array}{c}\text { La Niña } \\
(\mathrm{n}=18)\end{array}$ \\
\hline Spring $(\mathbf{L}=\mathbf{0})$ & & & \\
C1 & $-0.08 \pm 0.87$ & $+0.07 \pm 0.63$ & $+0.47 \pm 0.99$ \\
C2 & $-0.25 \pm 0.84$ & $-0.04 \pm 0.59$ & $+0.16 \pm 0.75$ \\
C3 & $-0.37 \pm 0.71$ & $-0.34 \pm 0.83$ & $+0.17 \pm 0.76$ \\
Summer $(\mathbf{L}=\mathbf{1})$ & & & \\
C1 & $-0.11 \pm 0.77$ & $-0.14 \pm 0.62$ & $-0.27 \pm 0.68$ \\
C2 & $+0.26 \pm 1.16$ & $-0.01 \pm 0.55$ & $-0.16 \pm 0.59$ \\
C3 & $+0.30 \pm 0.75$ & $-0.11 \pm 0.63$ & $+0.03 \pm 0.47$ \\
C4 & $-0.20 \pm 0.77$ & $-0.16 \pm 0.81$ & $-0.12 \pm 1.08$ \\
Autumn $(\mathbf{L}=\mathbf{2 )}$ & & & \\
C1 & $+0.03 \pm 0.57$ & $+0.01 \pm 0.71$ & $-0.29 \pm 0.67$ \\
C2 & $+0.16 \pm 0.70$ & $+0.08 \pm 0.80$ & $-0.12 \pm 0.69$ \\
C3 & $-0.04 \pm 0.52$ & $-0.12 \pm 0.60$ & $-0.07 \pm 0.67$ \\
C4 & $+0.10 \pm 0.83$ & $+0.07 \pm 0.97$ & $+0.36 \pm 0.63$ \\
\hline
\end{tabular}

areas. This result agrees with the enhanced precipitation detected over the Mediterranean during the boreal summer (Ropelewski \& Halpert 1987, Moron \& Ward 1998). The probability of dry conditions for Cluster 2 is similar under El Niño (26\%) and under La Niña $(28 \%)$. A possible explanation is the low amount of rainfall in summer in this area.

\subsubsection{Summer ENSO}

Table 10 shows the parameters of the empirical distributions of rainfall series under different summer ENSO phases. There were significant differences between the autumn rainfall corresponding to Cluster 1 (SW area), Cluster 2 (NW area), and Cluster 3 (Mediterranean area). The mean value of rainfall distributions was positive under El Niño, and negative under La Niña. This is similar to the patterns found by Rocha (1999) and Lloyd-Hughes \& Saunders (2002). In winter,

Table 9. Empirical probability (\%) of dry $(\mathrm{C}<\mathrm{P} 25)$ and wet (C > P75) seasons for each spring ENSO phase during 1912-2000. Threshold values are the 25th and 75th percentiles of the reference period 1961-1990. Only cases with significant differences between means and/or variances are shown (bold: significant probabilities at the $95 \%$ confidence level)

\begin{tabular}{|c|c|c|c|c|c|c|}
\hline \multirow[t]{2}{*}{ Cluster } & \multicolumn{2}{|c|}{ El Niño } & \multicolumn{2}{|c|}{ ENSOn } & \multicolumn{2}{|c|}{ La Niña } \\
\hline & Dry & Wet & Dry & Wet & Dry & Wet \\
\hline \multicolumn{7}{|l|}{ Spring } \\
\hline C3 & 39.1 & 13.0 & 45.8 & 16.7 & 5.6 & 33.3 \\
\hline \multicolumn{7}{|l|}{ Summer } \\
\hline $\mathrm{C} 2$ & 26.1 & 34.8 & 18.8 & 27.1 & 27.8 & 11.1 \\
\hline C3 & 26.1 & 39.1 & 29.2 & 16.7 & 11.1 & 16.7 \\
\hline
\end{tabular}


Table 10. Empirical distribution (mean $\pm \mathrm{SD}$ ) and number of data (n) for the rainfall seasonal series corresponding to each cluster and the summer ENSO phase, for lags $\mathrm{L}=0,1$, 2 seasons

\begin{tabular}{|lccc|}
\hline \multicolumn{1}{|c}{ Cluster } & $\begin{array}{c}\text { El Niño } \\
(\mathrm{n}=20)\end{array}$ & $\begin{array}{c}\text { ENSOn } \\
(\mathrm{n}=47)\end{array}$ & $\begin{array}{c}\text { La Niña } \\
(\mathrm{n}=22)\end{array}$ \\
\hline Summer $(\mathbf{L}=\mathbf{0})$ & & & \\
C1 & $-0.03 \pm 0.68$ & $-0.19 \pm 0.65$ & $-0.22 \pm 0.71$ \\
C2 & $+0.35 \pm 1.07$ & $-0.03 \pm 0.70$ & $-0.13 \pm 0.47$ \\
C3 & $+0.28 \pm 0.78$ & $-0.02 \pm 0.59$ & $-0.12 \pm 0.60$ \\
C4 & $+0.04 \pm 1.05$ & $-0.13 \pm 0.86$ & $-0.41 \pm 0.58$ \\
Autumn $(\mathbf{L}=\mathbf{1})$ & & & \\
C1 & $+0.27 \pm 0.63$ & $+0.03 \pm 0.66$ & $-0.48 \pm 0.53$ \\
C2 & $+0.44 \pm 0.69$ & $+0.12 \pm 0.78$ & $-0.43 \pm 0.43$ \\
C3 & $+0.25 \pm 0.57$ & $-0.12 \pm 0.57$ & $-0.33 \pm 0.51$ \\
C4 & $+0.18 \pm 0.70$ & $+0.21 \pm 0.93$ & $-0.07 \pm 0.89$ \\
Winter $(\mathbf{L}=\mathbf{2})$ & & & \\
C1 & $-0.01 \pm 0.78$ & $-0.20 \pm 0.86$ & $-0.19 \pm 0.70$ \\
C2 & $-0.21 \pm 0.73$ & $-0.02 \pm 0.74$ & $+0.06 \pm 0.65$ \\
C3 & $+0.18 \pm 0.99$ & $-0.17 \pm 1.04$ & $-0.46 \pm 1.08$ \\
\hline
\end{tabular}

this only occurred in Cluster 3 (northern area). In all 4 cases, mean values are within the interquartile interval of the reference period (Fig. 5). As a result, the probability of drought is $<15 \%$ for El Niño and the probability of abundant rainfall is $<20 \%$ for La Niña (Table 11). In addition, there are significant differences between variances corresponding to summer Clusters 2 (NE area) and 4 (SW area). For Cluster 2 and El
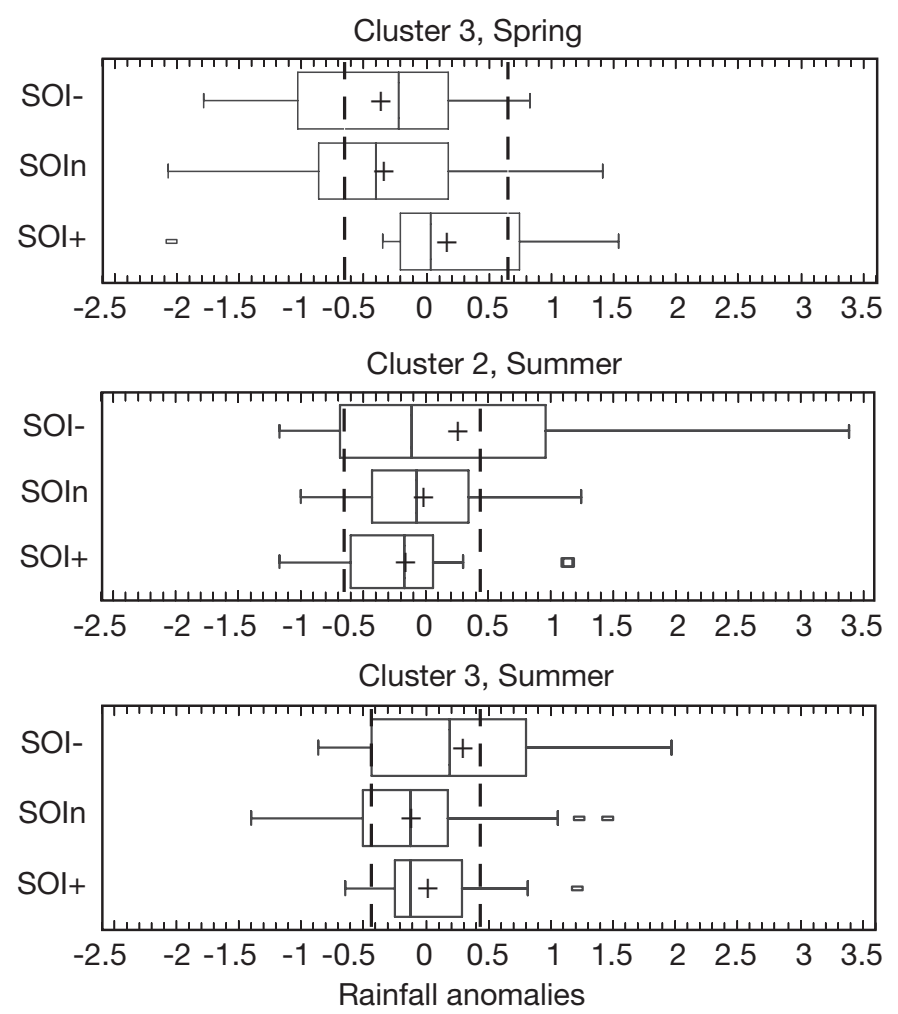

Fig. 4. Same as Fig. 3, for spring ENSO phases
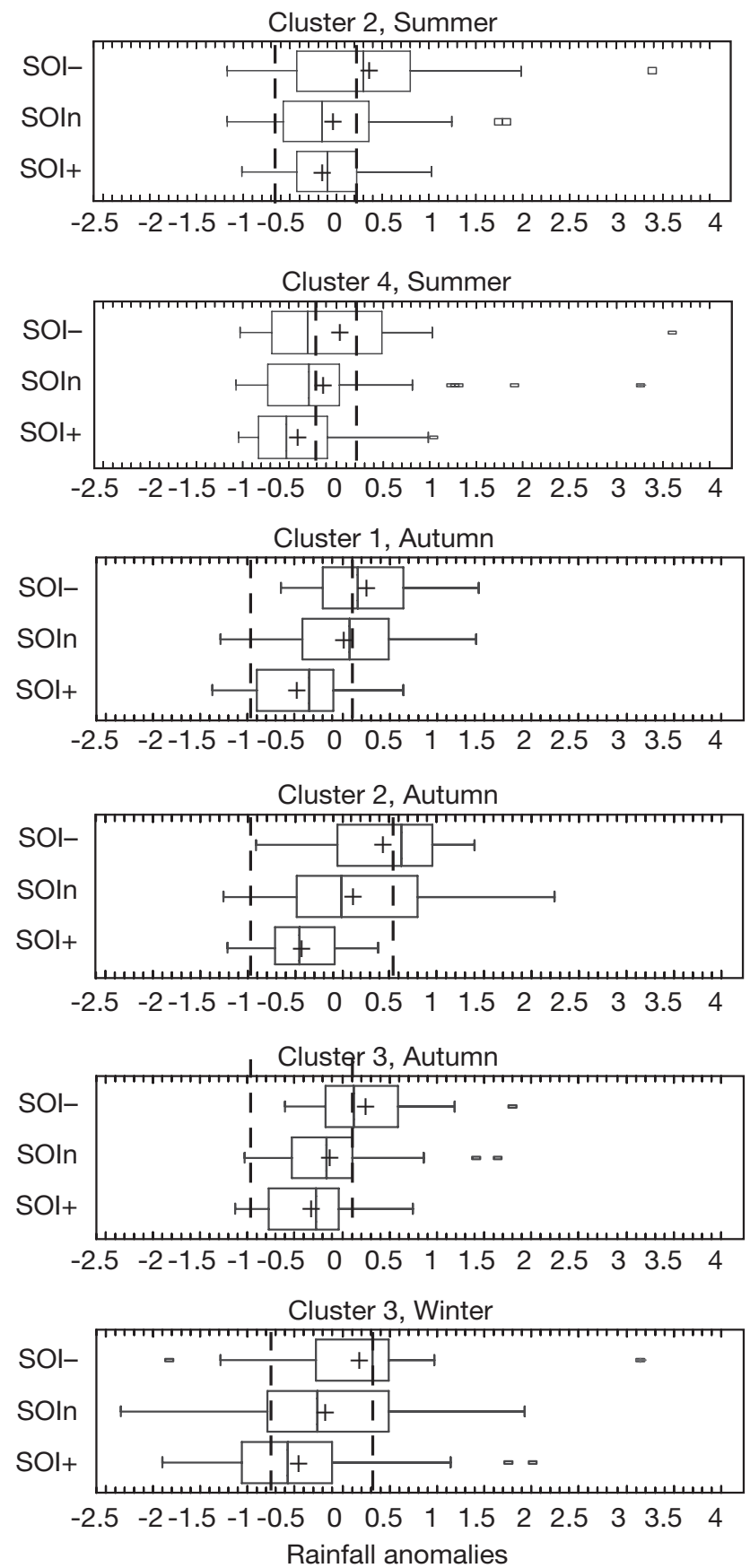

Fig. 5. Same as Fig. 3, for summer ENSO phases

Niño, the mean is $>$ P75 of the reference period, and for Cluster 4 and La Niña it is $<$ P25 of the reference period (Fig. 5). For these areas, the probability of wet conditions is higher under El Niño than for La Niña. This indicates a high probability of dry conditions under La Niña in SW Spain in summer and in the north in winter, as well as low probabilities of dry conditions under El Niño and of wet conditions under La Niña in autumn. 
Table 11. Empirical probability (\%) of dry $(\mathrm{C}<\mathrm{P} 25)$ and wet (C > P75) seasons for each summer ENSO phase during 1912-2000. Threshold values are the 25th and 75th percentiles of the reference period 1961-1990. Only cases with significant differences between means and/or variances are shown (bold: significant probabilities at the $95 \%$ confidence level)

\begin{tabular}{|lcccccc|}
\hline \multirow{2}{*}{ Cluster } & \multicolumn{2}{c}{ El Niño } & \multicolumn{2}{c|}{ ENSOn } & \multicolumn{2}{c}{ La Niña } \\
& Dry & Wet & Dry & Wet & Dry & Wet \\
& & & & & & \\
Summer & & & & & & \\
C2 & 20.0 & $\mathbf{4 5 . 0}$ & 25.5 & 25.5 & 18.2 & 9.1 \\
C4 & 40.0 & 35.0 & 46.8 & 19.2 & $\mathbf{6 8 . 2}$ & $\mathbf{9 . 1}$ \\
Autumn & & & & & & \\
C1 & $\mathbf{0 . 0}$ & 25.0 & 12.8 & 19.8 & 36.4 & $\mathbf{4 . 5}$ \\
C2 & $\mathbf{1 0 . 0}$ & 35.0 & 17.0 & 21.3 & 27.3 & $\mathbf{0 . 0}$ \\
C3 & $\mathbf{0 . 0}$ & 35.0 & 14.9 & 14.9 & 31.8 & $\mathbf{4 . 5}$ \\
Winter & & & & & & \\
C3 & 15.0 & 15.0 & 30.4 & 21.7 & $\mathbf{5 0 . 0}$ & 18.2 \\
\hline
\end{tabular}

\section{DISCUSSION}

The seasonal ENSO indices are correlated with levels of precipitation in Spain, not only with increasing or decreasing rainfall, but also with changes in the probabilities of extreme rainfall and with the spatial distribution of its impacts.

In autumn, El Niño yields null probability of drought and La Niña low probability of wet conditions in the same autumn in the whole country, except the northern area. In the following spring, El Niño leads to drought and La Niña to null probability of drought in the Mediterranean area of the Iberian Peninsula.

Winter ENSO influence is not detected, perhaps as consequence of the predominance of the NAO.

In spring, La Niña leads to a significant low probability of drought in the northern area in the same spring.

In summer, La Niña leads to a high probability of dry conditions in SW Spain in summer, and in the northern area in the following winter; El Niño leads to low probabilities of dry conditions in the following autumn, and La Niña to low probabilities of wet conditions.

These results are in good agreement with previously reports, and allow quantitative estimates of the probability of climate risks associated with ENSO phases in the study area (summarized in Tables 6, 9 \& 11) and their potential prediction. If the ENSO can be predicted, it may allow the estimation of seasonal rainfall anomalies several months in advance, which is of interest for agricultural and water management. The probabilities shown in Tables 6, 9 \& 11 will allow other users to calculate the expected expenses for a range of threshold values, by incorporating their own cost and loss information, in the sense described e.g. by Palmer et al. (2000). In this approach, the users can calculate the expected expense $M$ as

$$
M=\min .(\mathrm{p} L, C)
$$

where $\mathrm{p}$ is the probability of the climate event (Tables $6,9 \& 11$ ), $L$ the loss that they would suffer if the event occurred and they had not taken action to avert the loss or insure against it, and $C$ is the cost of taking action to avert or insure against the loss.

The influence of ENSO detected on contemporaneous seasons or with one or 2 seasons lagged, along with the different behaviour of the rainfall anomalies in each season suggests that the influence of the ENSO on Spanish rainfall may originate from different mechanisms. Some authors have argued that there is a lag of at least 3 mo between the beginning of an ENSO event and the extratropical response in higher latitudes in the North Pacific area (Trenberth \& Hurrell 1994). This response often resembles the Pacific North American pattern (PNA). This perturbation can be propagated downstream as a wave train to other longitudes in the form of Rossby waves, eventually affecting locations far away from the Pacific, particularly the North Atlantic region, and thus affecting the behaviour of NAO. Consequently, the eventual propagation of such events to other longitudes takes place with a similar lag. An alternative mechanism invokes anomalous Walker circulation, leading during El Niño (La Niña) phases to increased (decreased) subsidence over the tropical North Atlantic, and to a rise (decrease) in SSTs (Lloyd-Hughes \& Saunders 2002). On the other hand, there is evidence of an ENSO connection involving Indian monsoon rainfall and Mediterranean circulation. This connection seems to lead to enhanced precipitation over the Mediterranean in summer in El Niño years (Moron \& Ward 1998). Further work is needed to evaluate these teleconnections.

The ENSO relationship is unstable in time, and the strength of the teleconnection has varied over the past century (Díaz et al. 2001). At the interannual time scale, previous studies found a weak and unstable relationship between ENSO and North Atlantic atmospheric circulation (Moron \& Plaut 2003). Rodó et al. (1997) found that in the first half of the 20th century there was no significant signal associated with ENSO in any of stations of the Iberian Peninsula. Moron \& Plaut (2003) also noted a possible intensification of ENSO in the second half of the 20th century. A first approach to study this problem in our dataset would consist in comparing the first and second halves of the records, i.e. $1912-1956$ vs. 1957-2000. The number of ENSO events in each half is very similar (e.g. in autumn 11 vs. 12 events of El Niño, and 10 vs. 11 events of La Niña ) and the total number of cases cases is too small to resolve the question. A new criterion to establish threshold values, for instance, $\bar{I} \pm 0.7$ SD (Pozo-Vázquez et al. 2005), may help to address this problem. The non-stationary and decadal variations in ENSO relationships with rainfall in Spain will be explored in future studies. 
Acknowledgements. The Spanish Science and Education Ministery project CGL2004-05340-C02-02/CLI has funded this study. We acknowledge the very helpful comments made by the anonymous reviewers.

\section{LITERATURE CITED}

Almarza C, López JA, Flores C (1996) Homogeneidad y variabilidad de los registros históricos de precipitación en España. Instituto Nacional de Meteorología, Madrid

Bailey JS (1998) Temperature anomalies in high northerly latitudes and thei link with the El Niño/Southern Oscillation. Ann Geophysicae 16:1523-1526

Brown DP, Comrie AC (2002) Sub-regional seasonal precipitation linkages to ENSO and PDO in the Southwest United States. Atmos Sci Lett 3:94-102

Díaz H, Hoerling M, Eischeid J (2001) ENSO variability, teleconnections and climate change. Int $\mathrm{J}$ Climatol 21: 1845-1862

Dong BW, Sutton RT, Jewson SP, O'Neill A, Slingo JM (2000) Predictable winter climate in the North Atlantic sector during the 1997-1999 ENSO cycle. Geophys Res Lett 27: 985-988

Esteban-Parra MJ, Rodrigo FS, Castro-Díez Y (1998) Spatial and temporal patterns of precipitation in Spain for the period 1880-1992. Int J Climatol 18:1557-1574

Fraedrich K (1990) European Grosswetter during the warm and cold extremes of the El Niño Southern Oscillation. Int J Climatol 10:21-31

Fraedrich K (1993) An ENSO impact on Europe? A review. Tellus 46A: 541-552

Fraedrich K, Müller K (1992) Climate anomalies in Europe associated with ENSO extremes. Int J Climatol 12:25-31

Gershunov A, Barnett TP (1998) Interdedal modulation of ENSO teleconnections. Bull Am Met Soc 79:2715-2725

Goodess C, Jones PD (2002) Links between circulation and changes in the characteristics of Iberian rainfall. Int J Climatol 22:1593-1615

Halpert MS, Ropelewski CF (1992) Surface temperature patterns associated with the SO. J Clim 5:577-593

Hamilton K (1988) A detailed examination of the extratropical response to tropical ENSO events. J Clim 8:67-86

Hulme M, Sheard N (1999) Climate change scenarios for the Iberian Peninsula. Climatic Research Unit, University of East Anglia

Katz RW, Brown BG (1992) Extreme events in a changing climate: variability is more important than averages. Clim Change 21:289-302

Kiladis N, Díaz HF (1989) Global climatic anomalies associated with extremes of the Southern Oscillation. J Clim 2: 1069-1090

Knippertz P, Ulbrich U, Marques F, Corte-Real J (2003) Decadal changes in the link between El Niño and springtime North Atlantic Oscillation and European-North African rainfall. Int J Climatol 23:1293-1311

Laita M, Grimalt M (1997) Vorticity and pressure anomalies in the Western Mediterranean during El Niño/Southern Oscillation extremes. Int J Climatol 17:475-482

Lana X, Burgueño A (2000) Some statistical characteristics of monthly and annual pluviometric irregularity for the Spanish Mediterranean Coast. Theor Appl Climatol 65: 79-97

Lloyd-Hughes B, Saunders MA (2002) Seasonal prediction of European spring precipitation from El Niño-Southern Oscillation and local sea-surface temperatures. Int $\mathrm{J}$ Climatol 22:1-14
Lucero OA (1998) Effects of the Southern Oscillation on the probability for climatic categories of monthly rainfall, in a semi-arid region in the southern mid-latitudes. Atmos Res 49:337-348

Martínez Arias R (1999) El análisis multivariante en la investigación científica. Editorial La Muralla S.A., Madrid

May W, Bengtsson L (1998) The signature of ENSO in the Northern Hemisphere midlatitude seasonal mean flow and high-frequency intraseasonal variability. Met Atmos Phys 69:81-100

Mearns LO, Katz RW, Schneider SH (1984) Extreme hightemperature events: changes in their probabilities with changes in mean temperature. J Clim Appl Meteorol 23: 1601-1613

Moron V, Ward MN (1998) ENSO teleconnections with climate variability in the European and African sectors. Weather 53:287-295

Moron V, Gouirand I (2003) Seasonal modulation of the El Niño-Southern Oscillation relationship with sea level pressure anomalies over the North Atlantic in OctoberMarch 1873-1996. Int J Climatol 23:143-155

Moron V, Plaut G (2003) The impact of El Niño-Southern Oscillation upon weather regimes over Europe and the North Atlantic during boreal winter. Int J Climatol 23:363-379

Muñoz-Díaz D, Rodrigo FS (2004a) Impacts of the North Atlantic Oscillation on the probability of dry and wet winters in Spain. Clim Res 27:33-43

Muñoz-Díaz D, Rodrigo FS (2004b) Spatio-temporal patterns of seasonal rainfall in Spain (1912-2000) using cluster and principal component analysis: comparison. Ann Geophys 22:1435-1448

Ojo SF, Afiesimama EA (2000) Uso de promedios de periodos de referencia para examinar anomalías del clima. WMO, Boletín de la Organización Meteorológica Mundial 49: 288-291

Palmer TN, Brankovic C, Richardson DS (2000) A probability and decision model analysis of PROVOST seasonal multimodel ensemble integrations. Quart J Roy Meteorol Soc 126:2013-2033

Philander SGH (1990) El Niño, La Niña and the Southern Oscillation. Academic Press, San Diego

Pozo-Vázquez D, Esteban-Parra MJ, Rodrigo FS, CastroDíez Y (2001) The association between ENSO and winter atmospheric circulation and temperature in the North Atlantic region. J Clim 16:3408-3420

Pozo-Vázquez D, Gámiz-Fortis SR, Tovar-Pescador J, Esteban-Parra MJ, Castro-Díez Y (2005) El Niño-Southern Oscillation events and associated european winter precipitation anomalies. Int J Climatol 25:17-31

Quadrelli R, Pavan V, Molteni F (2001) Wintertime variability of Mediterranean precipitation and its links with largescale circulation anomalies. Clim Dyn 17:457-466

Rasmusson EM, Carpenter TH (1982) Variations in tropical sea surface temperature and surface wind fields associated with the Southern Oscillation/El Niño. Mon Weather Rev 115:3078-3096

Rocha A (1999) Low-frequency variability of seasonal rainfall over the Iberian Peninsula and ENSO. Int J Climatol 19: 889-901

Rodó X, Baert E, Comín FA (1997) Variations in seasonal rainfall in southern Europe during the present century: relationships with the North Atlantic Oscillation and the El Niño-Southern Oscillation, Clim Dyn 13:275-284

Rodríguez-Puebla CA, Encinas H, Nieto S, Garmendia J (1998) Spatial and temporal patterns of annual precipitation variability over the Iberian Peninsula. Int J Climatol 18:299-316 
Ropelewski CF, Jones PD (1987) An extension of the TahitiDarwin Southern Oscillation index. Mon Wea Rev 115: 2161-2165

Ropelewski CF, Halpert MS (1987) Global and regional precipitation patterns associated with the ENSO. Mon Wea Rev 115:1606-1626

Ropelewski CF, Halpert MS (1996) Quantifying SO-precipitation relationships. J Clim 9:1043-1059

Sumner H, Homar V, Ramis C (2001) Precipitation seasonality in eastern and southern coastal Spain. Int J Climatol 21:219-247

Trenberth KE (1984) Signal versus noise in the Southern Oscillation. Monthly Weather Review 112:327-333

Trenberth KE (1997) The definition of El Niño. Bull Am Met Soc 78:2771-2777

Trenberth KE, Hurrell JW (1994) Decadal atmosphere-ocean variations in the Pacific. Clim Dyn 9:303-319

Editorial responsibility: Otto Kinne,

Oldendorf/Luhe, Germany
Van Loon H, Madden RA (1981) The Southern Oscillation. Part I: global associations with pressure and temperature in the northern winter. Month Weather Rev 104: 1354-1361

Van Oldenborgh GJ, Burgers G, Tank AK (2000) On the El Niño teleconnection to spring precipitation in Europe. Int J Climatol 20:565-574

Von Storch H, Zwiers FW (1999) Statistical analysis in climate research. Cambridge University Press, Cambridge

Wigley TML (1985) Impact of extreme events. Nature 316: 106-107

Wilby RL (1993) Evidence of ENSO in the synoptic climate of the British Isles since 1880. Weather 48:234-239

Yulaeva E, Wallace JM (1994) The signature of ENSO in global temperature and precipitation derived from the microwave sounding unit. J Clim 7:1719-1736

Submitted: July 14, 2005; Accepted: November 1, 2005

Proofs received from author(s): December 12, 2005 